\title{
Commentary: Perhaps a limitation of youth?
}

\author{
Magdy M. El-Sayed Ahmed, MD, MS, a,b and \\ Kevin P. Landolfo, MD, MS
}

Neurocognitive dysfunction (NCD) occurs as a common complication following cardiopulmonary bypass (CPB) in as many $20 \%$ to $70 \%$ of patients. ${ }^{1}$ Furthermore, early postoperative NCD predicts poorer long-term functional outcomes. ${ }^{2}$ Although the mechanism of postoperative NCD may be mediated by neuroinflammation and endothelial dysfunction, the etiology remains unproven, with multiple potentiating triggers. ${ }^{3-5} \mathrm{CPB}$ causes a systemic inflammatory response in patients undergoing cardiac surgery, attributed to the combination of activation of blood components in the $\mathrm{CPB}$ circuit, ischemia/reperfusion injury, surgical trauma, and release of endotoxins. ${ }^{6-9}$ Activation of the body's major host defensive pathways and release of complement, coagulation factors, kinins, fibrinolysis, leukocytes, platelets, and inflammatory cytokines has been demonstrated.

Early assessment and identification of NCD in patients early after cardiac surgery facilitates the ability to treat and mitigate the long-term effects of this complication on outcomes and quality of life. In the current issue of the Journal, Anderson and colleagues $^{10}$ explore NCD following cardiac surgery as function of age. An experienced group of neurocognitive researchers identified a small group of patients (15 total) with NCD. Neurocognitive testing was administered preoperatively and postoperative day 4 (POD4) using the Repeatable Battery of Assessment of Neurological Status. Patients were then

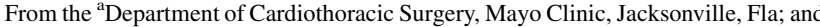
${ }^{\mathrm{b}}$ Department of Surgery, Zagazig University Faculty of Human Medicine, Zagazig, Egypt.

Disclosures: The authors reported no conflicts of interest.

The Journal policy requires editors and reviewers to disclose conflicts of interest and to decline handling or reviewing manuscripts for which they may have a conflict of interest. The editors and reviewers of this article have no conflicts of interest.

Received for publication Nov 25, 2019; revisions received Nov 25, 2019; accepted for publication Dec 12, 2019; available ahead of print March 30, 2020.

Address for reprints: Kevin P. Landolfo, MD, MS, 4500 San Pablo Rd S, Jacksonville, FL 32224 (E-mail: ahmed.magdy@ mayo.edu).

JTCVS Open 2020;1:10-1

2666-2736

Copyright (c) 2020 by The Authors. Published by Elsevier Inc. on behalf of The American Association for Thoracic Surgery. This is an open access article under the CC BY-NC-ND license (http://creativecommons.org/licenses/by-nc-nd/4.0/).

https://doi.org/10.1016/j.xjon.2019.12.001
}

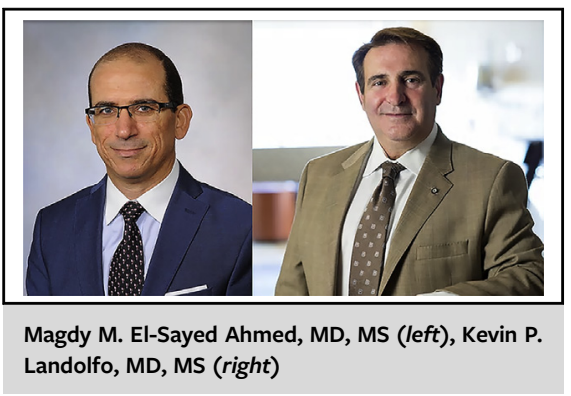

CENTRAL MESSAGE

Neurocognitive dysfunction

(NCD) following cardiopulmo-

nary bypass remains a significant

problem. Causes of NCD are

multifactorial, but younger age

and the inflammatory response

may play a role.

arbitrarily dichotomized into "youngest" ( $<60$ years) and "oldest" ( $>75$ years) groups for analysis. Although patients in the youngest group had greater baseline neurocognitive scores, they experienced a significant decrease in neurocognitive scores at POD4 from baseline. In contrast, no significant difference in neurocognitive scores from baseline and POD4 existed for the oldest patients, and there were no significant differences between the age groups at POD4. Inflammatory markers (interleukin [IL]-6, $\mathrm{C}$-reactive protein, tumor necrosis factor- $\alpha$ ) were measured. IL-6 and CRP were significantly greater at 6 hours and POD4, with IL-6 levels significantly greater in the youngest patients at 6 hours. However, no direct relationship between NCD and elevation of inflammatory markers was demonstrated.

Overall, the authors demonstrate that despite greater preoperative functional levels, significant neurocognitive decline does occur in the youngest patients. Because inflammatory markers (IL-6) increase to a greater degree among the youngest patients, the authors suggest inflammation as a possible mechanism for NCD, although a causal relationship was not proven. Major limitations of this study include single-center, very small sample size design. Further data are essential to be able to generalize these results. However, the proven relationship between early NCD, long-term neurocognitive outcomes, and poorer functional status following cardiac surgery highlights the importance of 
these findings. In particular, the impact of NCD in younger patients could be significant on individual patients as well as society in general.

\section{References}

1. Stroobant N, Van Nooten G, Van Belleghem Y, Vingerhoets G. The effect of CABG on neurocognitive functioning. Acta Cardiol. 2010;65:557-64.

2. Inouye SK, Marcantonio ER, Kosar CM, Tommet D, Schmitt EM, Travison TG, et al. The short-term and long-term relationship between delirium and cognitive trajectory in older surgical patients. Alzheimers Dement. 2016;12: 766-75.

3. Wilk CM, Gold JM, Bartko JJ, Dickerson F, Fenton WS, Knable M, et al. Testretest stability of the repeatable battery for the assessment of neuropsychological status in schizophrenia. Am J Psychiatry. 2002;159:838-44.

4. Xie G, Zhang W, Chang Y, Chu Q. Relationship between perioperative inflammatory response and postoperative cognitive dysfunction in the elderly. Med Hypotheses. 2009;73:402-3.
5. Moller J, Cluitmans P, Rasmussen LS, Houx P, Rasmussen H, Canet J, et al. Long-term postoperative cognitive dysfunction in the elderly: ISPOCD1 study. Lancet. 1998;351:857-61.

6. Prondzinsky R, Knupfer A, Loppnow H, Redling F, Lehmann DW, Stabenow I, et al. Surgical trauma affects the proinflammatory status after cardiac surgery to a higher degree than cardiopulmonary bypass. J Thorac Cardiovasc Surg. 2005; 129:760-6.

7. Bittar N, Koke JR, Berkoff HA, Kahn DR. Histochemical and structural changes in human myocardial cells after cardiopulmonary bypass. Circulation. 1975; 52(suppl):I16-25.

8. Freeman R, Gould FK. Rises in antibody to enteric gram-negative bacilli after open heart surgery: a possible mechanism for postoperative pyrexia. Thorax. 1985;40:538-41.

9. Chenoweth DE, Cooper SW, Hugli TE, Stewart RW, Blackstone EH, Kirklin JW Complement activation during cardiopulmonary bypass: evidence for generation of C3a and C5a anaphylatoxins. N Engl J Med. 1981;304:497-503.

10. Anderson K, Ziegler O, Shi G, Sodha N, Ikeda I, Feng J, et al. Younger age is associated with greater early neurocognitive decline postcardiopulmonary bypass. J Thorac Cardiovasc Surg Open. 2020;1:1-9. 